\title{
Increasing nutrition knowledge and food-related behavior practices among participants in the "Dining with Diabetes" program in West Virginia
}

Amy B. O'Dell

West Virginia University

Follow this and additional works at: https://researchrepository.wvu.edu/etd

\section{Recommended Citation}

O'Dell, Amy B., "Increasing nutrition knowledge and food-related behavior practices among participants in the "Dining with Diabetes" program in West Virginia" (2000). Graduate Theses, Dissertations, and Problem Reports. 1134.

https://researchrepository.wvu.edu/etd/1134

This Thesis is protected by copyright and/or related rights. It has been brought to you by the The Research Repository @ WVU with permission from the rights-holder(s). You are free to use this Thesis in any way that is permitted by the copyright and related rights legislation that applies to your use. For other uses you must obtain permission from the rights-holder(s) directly, unless additional rights are indicated by a Creative Commons license in the record and/ or on the work itself. This Thesis has been accepted for inclusion in WVU Graduate Theses, Dissertations, and Problem Reports collection by an authorized administrator of The Research Repository @ WVU. For more information, please contact researchrepository@mail.wvu.edu. 


\title{
INCREASING NUTRITION KNOWLEDGE AND FOOD RELATED BEHAVIOR PRACTICES AMONG PARTICIPANTS IN THE “DINING WITH DIABETES” PROGRAM IN WEST VIRGINIA
}

\author{
Amy O'Dell \\ Thesis Submitted to The College of Agriculture, Forestry, and Consumer \\ Sciences \\ at \\ West Virginia University \\ in Partial Fulfillment of the Requirement for the \\ degree of \\ Master of Science \\ In \\ Family and Consumer Sciences
}

M. Zafar A. Nomani, Ph.D., R.D., Chair

Guendoline Brown, Ph.D.

Carol Markstrom, Ph.D.

Division of Family and Consumer Sciences

Morgantown, West Virginia

2000

Keyword: diabetes, diabetes education, nutrition knowledge, behavior change

Copyright 2000 Amy O’Dell 


\title{
ABSTRACT \\ INCREASING NUTRITION KNOWLEDGE AND FOOD RELATED BEHAVIOR PRACTICES AMONG PARTICIPANTS IN THE “DINING WITH DIABETES” PROGRAM IN WEST VIRGINIA
}

\begin{abstract}
Amy O’Dell
Diabetes is a serious disease that effects a large number of the population of the United States, including West Virginia. Many diabetics lack the understanding between diet and diabetes, which in turn makes it difficult for them to control the disease. The West Virginia University Extension Service provides a diabetes education program, "Dining with Diabetes", in an effort to help combat the severe complications associated with diabetes. A study was conducted using 591 diabetic and non-diabetic subjects from various counties throughout West Virginia. Participants attended a series of three twohour cooking/education sessions and a six-month reunion held six months after the initial sessions. A pretest and demographic form were completed during the first session and an identical posttest was completed during the 6-month reunion. Analysis was completed using ANOVA and Pearson's correlation to determine the effect the diabetes intervention program had on nutrition knowledge, self-reported behaviors, and diabetes practices. In the present set of subjects, the results indicated that there was no significant difference in nutrition knowledge between diabetic and non-diabetic subjects for the pretest and posttest scores. However, when the subjects were placed into three groups based on their pretest score, interaction between diabetic status and scholastic status was noted $(p<0.07)$ with nutrition knowledge. There was a trend for diabetic subjects to score slightly lower in the low-scoring group of subjects and slightly higher in the high-scoring group of subjects. When the pretest score was correlated with the change in score (posttest score pretest score) subjects who scored lower on the pretest had a higher improved score in the posttest compared with those subjects who scored high on the pretest $(r=-0.75, p<0.00)$. Significant association was also noted between nutrition knowledge score and several behavior and diabetic practices, for example checking blood sugar $(r=0.151, \mathrm{p}<0.5)$, using a diabetic meal plan $(\mathrm{r}=0.17, \mathrm{p}<0.02)$ and preparing healthy meals $(\mathrm{r}=0.156$, $\mathrm{p}<0.03$ ). Thus, the results conclude that diabetes education programs may significantly affect some behaviors and diabetic practices.
\end{abstract}




\section{Acknowledgements}

I would like to acknowledge and thank all of those individuals who have helped to make this possible.

To my thesis committee:

Dr. M. Zafar A. Nomani, advisor and chair, thank you for your encouragement, patience, and support.

Dr. Carol Markstrom, thank you for all of your suggestions, recommendations, and for serving on my committee

Dr. Guen Brown, thank you for giving me the wonderful opportunity to work with you, your friendship, and for never letting me give up.

To my family and friends:

I would like to thank my wonderful parents, Arnold and Ann, for believing in me. Words cannot express how thankful I am for the love and support you have given me throughout my life.

To Kevin, thank you for coming into my life. Your support, love, and friendship have guided me through this.

To all of my friends and family, thanks for your encouragement and support. I could never have made it this far without you. 


\section{Table of Contents}

Page

Abstract........................................................................ii

Acknowledgements............................................................iii

List of Tables and Figures.....................................................vi

Chapter I: Introduction.................................................................1

Statement of the Problem....................................................3

Objectives.....................................................................4

Chapter II: Review of Literature..............................................5

Diabetes Education.........................................................5

Diabetes Education Programs..............................................8

The Dining with Diabetes Program.......................................9

Behavior Change/Modification...........................................10

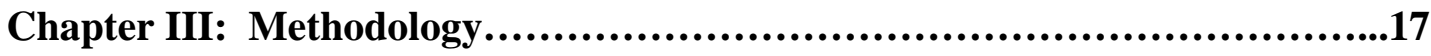

Research Design............................................................17

Study Population.......................................................17

Procedures.................................................................18

Session One: Desserts............................................19

Session Two: Main Dishes.......................................19

Session Three: Side Dishes......................................20

6-Month Reunion...................................................20

Instruments...........................................................20

Nutrition Knowledge Score Validation.................................20 
Nutrition Knowledge Score...............................................21

Behavior Score.........................................................22

Chapter IV: Results.......................................................23

Nutrition Knowledge....................................................24

Association of Nutrition Knowledge with Behavior and...................25

Diabetes Practices

Healthy Meal Plan.........................................................27

Chapter V: Discussion........................................................40

Nutrition Knowledge....................................................40

Behavior Change/Diabetes Practices.......................................42

Meal Plan............................................................43

Limitations and Recommendations for Future Research..................43

Chapter VI: Conclusions.....................................................46

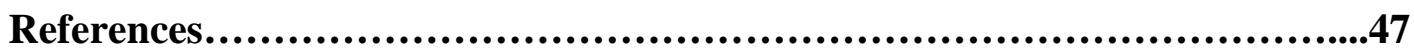

Appendices...................................................................50

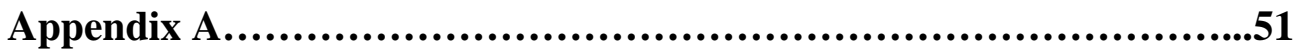

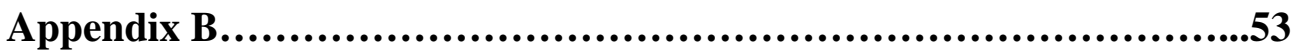

Appendix C...........................................................58

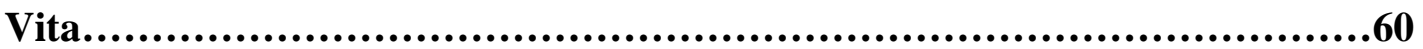




\section{List of Tables and Figures}

Tables

1. Validation of Knowledge Questionnaire...........................28

2. Diabetic Status of the Participants...............................29

3. Gender Characteristics of the Study Population..................30

4. Ethnic Groups Represented by the Study Population..............31

5. Age Groups Represented by the Study Population................32

6. Results of ANOVA, Nutrition Knowledge Score, with............33 Diabetes Status and Scholastic Status Groups.

7. Nutrition Knowledge Score of the Knowledge....................35 Questionnaire between Diabetic Status and Scholastic Status

8. Association Between Nutrition Knowledge Score and............37 Self-reported Behavior and Related Diabetes Practices

9. Percent of Subjects in Each Problem Associated with............38 Using a Diabetes Meal Plan (Pre-intervention)

10. Percent of Subjects in Each Problem Associated with...........39 Using a Diabetes Meal Plan (Post-intervention)

Figures

1. Nutrition Knowledge Score with Diabetic Status..................34 and Scholastic Status

2. The Association Between Pretest Score and Change in............36 Score Following the Posttest 


\section{Chapter I}

\section{Introduction}

Diabetes is a serious chronic disease that affects 16,000 million people in the United States, and only half of these cases have been diagnosed (Halperin et al, 1999). Diabetes is a nationwide problem, but the problem is just as severe in West Virginia. A recent report by the United States Department of Health and Human Services, Centers for Disease Control and Prevention stated, "in 1996, 77,972 adults in West Virginia had diagnosed diabetes" (USDHHS, 1999). According to a report by the USDHHS, "West Virginia had the third highest rate of death due to diabetes with 669 deaths and contributed to another 1,462 deaths" (USDHHS, 1999). In 1997, the disease was the seventh leading cause of death in both the United States and West Virginia contributing to a total of 62,332 deaths in the U.S. and 687 deaths in West Virginia. (West Virginia Bureau for Public Health, 1999).

"Diabetes mellitus is a group of metabolic diseases characterized by hyperglycemia resulting from defects in insulin secretion, insulin action, or both." (American Diabetes Association, 1997). There are several classifications of diabetes: Type 1 diabetes or insulin dependent diabetes mellitus (IDDM), Type 2 diabetes or noninsulin dependent diabetes mellitus (NIDDM), other specific types of diabetes, and finally gestational diabetes mellitus (GDM) (American Diabetes Association, 1997).

Type 1 diabetes is the result of the body's inability to produce insulin due to the breakdown of the insulin producing ( $\beta$ cells) which are located in the pancreas. Thus, insulin must be injected for survival of the individual (American Diabetes Association, 1997). 
The mechanism for Type 2 diabetes is insulin resistance and a defect in insulin secretion. In this type of diabetes, the individual cannot provide a sufficient amount of insulin to control increased blood glucose levels. Type 2 diabetes is the most prevalent form of diabetes, and the risk for developing this type of diabetes rises with increased weight, age, and a sedentary lifestyle (American Diabetes Association, 1997).

The American Diabetes Association also states a third class of diabetes that is caused by specific problems. These other specific types of diabetes are classified as genetic defects of $\beta$-cell function, genetic defects in insulin action, diseases of the exocrine pancreas, endocrinopathies, drug- or chemical-induced, infections, uncommon forms of immune-mediated diabetes and other genetic syndromes associated with diabetes. (American Diabetes Association, 1997).

Gestational diabetes mellitus or GDM is the final class of diabetes. This form of diabetes occurs during pregnancy and normally ceases following the termination of the pregnancy. There are approximately 135,000 cases of GDM every year in the United States (American Diabetes Association, 1997). Women who have gestational diabetes during their pregnancies are more likely to be diagnosed with Type 2 diabetes later in life.

The need for increased diabetes knowledge is crucial. Diabetics must understand their disease and the effects of its progression. Without this understanding complications of diabetes may occur which include: retinopathy, the potential loss of vision; renal failure resulting from neuropathy; an increased risk of cardiovascular disease; risk of limb amputations; and loss of sexual function (American Diabetes Association, 1997). 
Not only is it important that diabetics increase their knowledge about this disease, they must also change their behavior concerning food choices and cooking practices. These behavior changes are crucial for the lifestyle change that a diabetic must employ to help manage their disease. The Stages of Change approach is a useful tool for healthcare providers in determining where a diabetic lies along the spectrum of behavior change. For example, is the individual in the precontemplation stage, the contemplation stage, the preparation stage, the action stage, or the maintenance and relapse prevention stage? (Zimmerman et al., 2000).

There are many factors that increase a person's risk of developing diabetes, especially Type 2 diabetes. These risk factors include obesity, race/ethnicity, age of 45 years or older, hypertension, previous identified impaired fasting glucose or impaired glucose tolerance, high HDL and/or triglyceride levels; and a history of gestational diabetes (Florence and Yeager, 1999). Most of the risk factors are prevalent in West Virginia. A high proportion of West Virginia's population is considered obese.

Cardiovascular disease is common in West Virginia's population as well. West Virginia also is home to many individuals over the age of 45 years. Many West Virginian's embody risk factors associated with Type 2 Diabetes Mellitus.

\section{RESEARCH PROBLEM}

The objective of this study is to determine the effects of a diabetes cooking school intervention on the knowledge and self-reported behaviors and practices of diabetics and non-diabetics attending the diabetes cooking school.

The risk of developing diabetes is on the rise in West Virginia due to an increase in the risk factors associated with this disease i.e., obesity, increased age and 
cardiovascular disease. In 1997 approximately 687 deaths occurred in West Virginia due to diabetes mellitus, this is $37.8 \%$ of the WV Crude Rate. The nation's death rate due to diabetes mellitus was 62,332 or $23.3 \%$ of the US Crude Rate (West Virginia Bureau for Public Health, 1999).

Once an individual has been diagnosed with diabetes, it is essential that they understand the disease, how it affects the body, and how to control it. Without this understanding the disease may become uncontrolled thus damaging many organs and limbs including: the kidneys, heart, eyes, and lower limbs. However, if a diabetic has some understanding of the disease and practices necessary eating and health habits, this organ and limb damage may be prevented.

The West Virginia University Extension Service provides a program in an effort to increase knowledge and proper behavior practices in diabetics. This program, Dining with Diabetes, is offered to diabetics, family members of diabetics and diabetes caregivers in each county of West Virginia. A combination of diabetes education and cooking principles are taught during each of the three sessions.

\section{Objectives of the study}

1) Determine whether a diabetes intervention increases knowledge in diabetic and non-diabetic subjects.

2) Determine if any positive behavior change occurs as a result of the diabetes intervention program. 


\section{Chapter II}

\section{Review of Literature}

This Review of Literature was written to provide the most recent information about diabetes education and the impact it has on increasing a diabetic's knowledge level as well as positive behavior change. Studies have been conducted to find the relation between diabetes education and its effect on knowledge in diabetics. The following studies indicate various diabetes education programs and the impact these programs have on a diabetic subject's knowledge of the disease and/or behavior modification.

\section{Diabetes Education}

Maintaining or developing a healthy lifestyle is one of the most important things a diabetic can do in an effort to control their disease. Due to feelings of frustration, concern, and anxiety many diabetics will chose to do nothing to maintain a healthy lifestyle. This negligence may prove to be severe in later stages of life as many parts of the body may be damaged.

Diabetes education plays an important role in supporting lifestyle change and in turn may help reduce the severe effects of diabetes. Education decreases complications, increases awareness and self-care behaviors, and improves glycemic control. (Graziani, Rosenthal, \& Diamond, 1999). Educating diabetics and providing disease management skills may help decrease the complications of diabetes. (Allwinkle, 1998).

Although the objective of many diabetes education programs is to increase the knowledge level of participants, behavior change should be enforced. Diabetes education should be directed toward behavior change by enabling the diabetic to "modify old behaviors and initiate new behaviors." (Peyrot, 1999). According to Peyrot, "Knowledge 
is only a means to an end (behavior change), and only knowledge that facilitates behavior change is appropriate." (Peyrot, 1999). The following studies will emphasize the importance and need for diabetes education programs in the United States

A study by Bautista-Martinez et al., measured the knowledge levels of a group of Mexican individuals with diabetes. This study also examined factors that influenced knowledge. 570 subjects participated in this study. 63 subjects had Type 1 diabetes, 208 had Type 2 diabetes treated with insulin and 298 Type 2 diabetic subjects who controlled their diabetes without insulin.

The subjects completed a questionnaire, which was divided into several sections including general concepts of the disease, nutrition, exercise, self-monitoring of blood glucose, diabetes-related medications, and foot care. The results reveal that the Type 1 subjects had the highest mean score of correct answers followed by the insulin-treated Type 2 subjects. The Type 2 patients treated with an oral hypoglycemic agent (without insulin) had the lowest score.

These results further indicated that the subjects were lacking in diabetes education. The subjects with Type 1 diabetes scored higher on the questionnaire than the other two groups and also had a higher education level than the other groups. Also, individuals with complications of the disease had an incidence for a higher number of correct answers. Scores were significantly higher for subjects who had taken insulin, had attended a diabetes education class, and had a higher education level. The study also indicated that diabetics should attend diabetes education classes at the time of their diagnosis. This advanced education may increase knowledge in this area so that complications of the disease may be prevented. (Bautista-Martinez et al., 1999). 
A second study examined the knowledge and source of information of diabetic African American women and white women. The purposes of the study were to (1) "describe the sources of diabetes information among older women according to ethnicity (African American and white), (2) to analyze the relationship between information sources and outcome of a standard test of diabetes knowledge, and (3) to explore the relationship between information source, test scores, and ethnicity." (Schoenberg et al., 1998).

The subject groups for this study consisted of 51 women aged 65 years and older who were African American and white. These women completed a Diabetes Knowledge Test as well as an Inventory of Sources. African American women scored significantly lower on the Diabetes Knowledge than the white subjects with a $P$ value of 0.018 . The source of diabetes information had little affect on the Diabetes Knowledge Test, however ethnicity was significant in determining the knowledge of the subjects. These results indicate that diabetes education should be ongoing and that older women could greatly benefit from this education. (Shoenberg et al., 1998).

A study published in the Southern Medical Journal examined knowledge and behavior modification in subjects with Type 2 diabetes mellitus. The subjects were randomly divided into a control group and an intervention group. Subjects in both of the groups completed surveys related to diabetes knowledge and life skills at baseline, 6 months and 12 months. The subjects in the intervention group attended 6 months of sessions concerning diabetes knowledge and behavior modification. A follow-up session occurred at 12 months. Fasting blood glucose (FBG) level and weight were measured every month for 6 months and again at the twelfth month. Glycosylated hemoglobin 
(HGb) and low-density lipoprotein cholesterol (LDL-C) levels were assessed at 3, 6, and 12 month periods.

The results of this study show that the intervention group had a significant decrease in fasting blood glucose, mean GHb, mean LDL-C and mean total cholesterol. These results were not significant at the 12-month follow-up, however, decrease in body weight as well as improvements of diabetes knowledge were significant. The control group had a significant decrease in $\mathrm{GHb}$ and weight loss at the 6-month assessment, but these results were not significant at 12 months. (Ridgeway et al., 1999).

The previous studies have indicated how important diabetes education is in increasing the knowledge of diabetics as well as influencing positive behavior change. Diabetes education programs are essential to help make these changes.

\section{Diabetes Education Programs}

There are several national diabetes education programs. These programs are aimed at increasing awareness about diabetes as well as attempting to increase knowledge and influence behavior change in diabetics.

One such diabetes education program is the "Control Your Diabetes" campaign. The National Diabetes Education Program and the National Institute of Diabetes and Digestive and Kidney Diseases promote this program in order to increase the nation's awareness about diabetes. "Control Your Diabetes" encourages diabetics to control their blood sugar levels using healthy lifestyle practices. (Herreria, 1999).

The "Learn, Taste, and Share" program is a diabetes education program offered in Michigan. This program was developed following several focus groups that met in the African American community. The individuals attending the focus groups discussed the 
topics they would like to have covered in a diabetes education class. The feedback received during the focus groups was then implemented and with help from the local community, the "Learn, Taste, and Share" program was developed. (Hahn and Gordon, 1998).

The program was divided into 4 2-hour sessions in which nutrition education and hands-on cooking demonstrations were presented. Biochemical tests such as total glycohemoglobin, cholesterol, HDL and LDL cholesterol, the HDL: LDL ratio and triglycerides were measured at baseline and again at 6-month follow-up. The glycohemoglobin test was improved at the 6-month follow-up. The attendance and enthusiasm for the program was so great that an ongoing support group was started within the community. (Hahn and Gordon, 1998).

\section{The Dining with Diabetes Program}

The Dining with Diabetes program is based on the Social Cognitive Theory and the Stages of Change. The Social Cognitive Theory relies heavily on the concept of reciprocal determinism. The Social Cognitive Theory emphasizes interaction of the environment, participant, and behavior. (Olson, 1999). The Dining with Diabetes program also incorporates the Stages of Change into its curriculum and data collection instruments. This allows, "Measurement of knowledge, expectations, self-efficacy, and behavior change related to food intake and diabetes." (Olson, 1999). Increasing selfefficacy is a strong component of the Social Cognitive Theory. Self-efficacy is defined as "the belief that one can carry out a behavior necessary to reach a desired goal, that is, achieve an expected outcome." (Clark and Dodge, 1999). 
There are 6 Stages of Change: Precontemplation, Contemplation, Preparation, Action, Maintenance and Termination. An individual is considered to be in the Precontemplation stage when they are in denial and show no interest in behavior change. In the Contemplation stage an individual mediates. During this time the individual will often examine the positive and negative aspects of the change. For example, he/she may examine the positive aspects of following a healthy diet; such as being able to better regulate blood glucose levels and decreasing the risk for cardiovascular disease. The examination of such positive aspects will likely be compared with things that will be given up, for example the consumption of many high fat and high calorie foods. The Preparation stage enables the individual preparation to make the desired change. During the Preparation stage experimentation may take place. Individuals may try new foods that are permitted and recommended in their diet. In the Action stage, the individual would implement the foods into their diet. In the Maintenance stage, the behavior change has been maintained for at least six months. This may be one of the most difficult stages in behavior change. Termination occurs when no conscious effort is needed to maintain the behavior. It has been shown that even though individuals have "conquered" the first four stages of change, it is often difficult to maintain these changes and not have a relapse. (Harvard Heart Letter, 2000).

\section{Behavior Change/Modification}

Although it is vital that individuals with diabetes understand their disease, the complications associated with their disease, and how to control their disease, it is also essential that they understand the role that their lifestyle plays in helping to accomplish all of these things. Until the individual is willing to make behavior changes that will in 
turn change their lifestyle, increasing knowledge in the area of diabetes is somewhat useless. For example, it is easy for a diabetic to learn that he/she must follow a diet low in kilocalories, fat, and carbohydrates, however, if the diabetic is not willing to incorporate the diet into their daily life, then the information has proven to be exhausted. An article published in Wellness Perspectives examined the Stages of Change in relation to exercise. The purpose of the study "was to determine whether a recently developed scale, the Stage of Exercise scale, was able to differentiate between subjects' classified by stage of exercise on several behavioral and biometric physical activity indices." (Cardinal, 1995). The independent variable in this study was the stage of exercise the individual was in and biometric and behavioral measures were the dependent variables.

Questionnaires were used to determine the amount of time the individuals spent in leisure time exercise behavior, the frequency of sweat-induced exercise, body fat percentage, physical activity rating (PAR), VO, and finally difficulty with relapse. All of these were self-reported.

The results of the study indicate that despite the stage of change the individual classified him/herself in significantly differed in term of the other biometric and behavioral variables. Analysis of covariance (ANCOVA) revealed a significance of $\mathrm{p}<0.001$ between groups for the stage of exercise and weekly leisure time exercise. Frequency of sweat induced exercise, difficulty with relapse, PAR, and VO were all significant with $\mathrm{p}<0.001$.

It was reported that $32.5 \%$ or 26 of the 80 participants classified themselves as being in the Preparation stage for exercise, $25 \%$ reported that they were in the Action 
stage and $42.5 \%$ reported being in the Maintenance stage. However, these reported stages differed significantly in terms of time spent in leisure per week, frequency of exercise induced sweating, PAR, difficulty with relapse and VO. The results indicate that some individuals placed themselves in a higher stage of change than the dependent variables indicated. (Cardinal, 1995).

A second study incorporated nutrition behavior change materials into the Language for Health program. This heart disease prevention program was designed to lower the risk of cardiovascular disease in low-literacy populations. (Elder \& Candelaria, 2000). Participants from the Latino population who enrolled in the English-as-a-secondlanguage program were either placed in a heart disease prevention program, (intervention group) or a stress management program (placebo group).

Physiological and psychosocial assessments were measured at baseline, 3-months later, and 6-months from baseline. The physiological measurements consisted of blood pressure, total high-density lipoprotein (HDL) cholesterol, waist and hip circumference, and weight. The psychosocial assessments consisted of self-report surveys to determine demographic information, nutrition knowledge and attitudes, and fat-avoidance behaviors.

Because some of the participants completed the surveys given in English and some completed surveys given in Spanish, Chi-square and t-tests were used to determine any differences between these two groups. MANOVA was used to test for intervention effects.

The results show that there was significance in the intervention group in several areas from baseline to 3 month post-test. The areas where significance was found for the 
physiological measures were a decrease in total: HDL cholesterol ratio and a decrease in systolic blood pressure. Although systolic blood pressure decreased for the control group as well, the intervention had a greater decline in this value. These areas were only shortterm however, and were not significant at the 6-month follow-up.

Areas of significance were also found for several of psychosocial measures. For example the intervention group experienced an increase in fat avoidance scores and a greater change in the area of nutrition knowledge compared to the control group. The control group experienced a greater increase in the area of stress knowledge than did the intervention group.

Significance was found in the intervention group from 3-month post-test to 6month follow-up for total: HDL ratio and systolic blood pressure with p values $<0.05$. Fat avoidance and nutrition knowledge scores increased over time and were significant with $\mathrm{p}$ value $<0.001$. Conversely, the stress knowledge scores were increased in the control group and significance was found with p<0.001, (Elder and Candelaria, 2000).

A study conducted by Sorenson and Stoddard examined the "Effects of a health promotion-health protection intervention on behavior change." (Sorenson and Stoddard, 1998). This randomized control study used self-reported surveys to measure demographic information, exposure to workplace hazards and behavior changes for dietary habits and cigarette smoking over a 2-year period.

Several analyses were conducted to test intervention effects, effectiveness of the intervention while controlling for several variables, and continuous outcomes. The results of the analyses indicate significant reductions in fat consumption for the intervention group. Skilled and unskilled laborers in the intervention group increased 
fiber intake by 7 percentage points more than the control group. Workers in the intervention group also had an increase in the number of servings of fruits and vegetables with an increase of 0.23 servings/day compared to .10 servings/day for the control group. Smoking abstinence rates were also greater in the intervention work sites at $15 \%$ compared to $9 \%$ in the control group.

The results "indicate significant reductions in the percentage of calories consumed as fat and an increase in servings of fruits and vegetables." (Sorenson and Stoddard, 1998). Although smoking abstinence rates did not significantly increase, they did increase substantially among skilled and unskilled laborers in intervention group.

A study published in the Journal of the American Dietetic Association also examined behavior change. The objective of this study was to "evaluate the effect of a theory-based newsletter on knowledge, attitude and behavior change in older adults." (Taylor-Davis, et al., 2000). The study consisted of 480 men and women between the ages of 60 and 74. There were two intervention groups and a control group for this study. One intervention group received 5 newsletters over a 10-week period of time. This group also received a telephone interview after receiving each newsletter. The second intervention group received only the 5 newsletters.

Pre-tests given at baseline and post-tests given after the intervention were used to determine change is several aspects such as cognition, affection, and behavior. Nutrition knowledge and willingness to answer questions were classified as cognitive. Perceived nutrition knowledge and interest in nutrition were indicated as the affective aspect of the measure. The behavioral component of the pre and post-tests consisted of food behavior and the stage of change for dietary fat and fiber. 
Analysis of covariance was used to test for group differences between the pre-test and the post-test. Where significance was found, Duncan's post hoc test was used to determine the nature of the between group differences.

Results indicate significance in the each area of cognition, affection, and behavior. More subjects in the treatment group were willing to answer questions at posttest than the subjects in the control group. The treatment group that received newsletters and telephone interviews scored significantly higher for both of the cognition variables (willingness to answer questions and nutrition knowledge). The treatment groups also had higher scores in perceived nutrition knowledge and interest in nutrition than did the control group. The areas of improvement for cognition and affection were highest in the treatment group receiving newsletters and telephone interviews. The treatment groups also performed better than the control group for stages of change for dietary fiber and avoidance of fats. (Taylor-Davis et al., 2000).

The USDA developed an interactive CD-ROM program to produce dietary behavior change in fat, fruit and vegetable intake. "The design was based on principles of relevance to the learner, readiness for change, feedback, individualization, facilitation of skills, and goal setting." (Block et al., 2000). The program was offered to participants at a WIC (Women, Infant, and Children clinic), hospital lobby and waiting room, library, YMCA, and senior center mainly in low-income areas of the city. The program was offered free of charge to the participant.

This computer program would evaluate the stage of change each individual was in and would then provide tips or suggestions to help improve the individual's nutrition. $60 \%$ of the individuals selected a personal goal to try for 2 weeks and of the $60 \%, 46 \%$ 
said they would definitely try to achieve the goal and $37 \%$ said they would try to achieve it. Following the two weeks each of the 92 subjects was contacted by phone to determine the effectiveness of the goal. $50.5 \%$ said they committed to try to goal, $10 \%$ said they had tried to achieve the goal or had partial success. $2 / 3$ of those individuals who said they would definitely try to achieve their goal had followed through with completion. (Block et al., 2000).

The previous studies examined behavior and knowledge change following some type of intervention strategy. The interventions or treatments described earlier indicate significant improvements in knowledge and/or behavior for those individuals receiving the intervention. Although the intervention may not have included diabetes as its focus, the results of these interventions examined stages of change and other strategies that are indicative of the Dining with Diabetes program. 


\section{Chapter III}

\section{Methodology}

\section{Research Design}

A “one-group pretest-posttest design" (Campbell and Stanley, 1963) was used which is a faulty design. Although an intervention was provided in the study this design considered pre-experimental. This design was used to determine change in nutrition knowledge and self-reported behavior change and practices in diabetic and non-diabetic subjects involved in the Dining with Diabetes education program.

The independent variables in this study were (1) diabetes status: diabetic, nondiabetic subjects and (2) nutrition knowledge score. The dependent variables were the self-reported behaviors: the use of herbs or spices in place of salt, using olive or canola oil, using artificial sweeteners in desserts, controlling the amount of carbohydrates the individual eats, and associated diabetes practices.

\section{Study Population}

The study consisted of 591 participants who attended the Dining with Diabetes cooking school between the months of September and November 1999. There were 323 diabetic subjects and 234 non-diabetic subjects. The remaining 34 subjects were individuals who indicated that they were unsure whether or not they had diabetes or individuals who were under the age of 18 years. Information obtained from participants under 18 years of age was not included in data analysis. The study consisted of data collected from the following counties in West Virginia: Monongalia, Marion, Logan, Wood, Putnam, Mineral, Greenbrier, Wirt, Pocahontas, Braxton, Preston, Lewis, Upshur, Taylor, and Marshall. Two hundred and eight participants attended the reunions that 
were held 6 months following the initial sessions between the months of March and May 2000.

\section{Procedures}

The Dining with Diabetes program was offered to communities throughout West Virginia. This program is funded by the Centers for Disease Control and Prevention and the West Virginia Bureau for Public Health, Diabetes Control Program. West Virginia University's Extension Agents, Registered Dietitians (RD's), Certified Diabetes Educators (CDE's), Registered Nurses (RN's) and community volunteers worked collaboratively to deliver this program free of charge to diabetics, their family members and diabetes caregivers throughout West Virginia.

The program consisted of an educational or nutrition component, a cooking and tasting component and a social or fellowship component. A RD, CDE, or RN taught the educational/nutritional component of the program. The WVU Extension Agent provided the cooking demonstrations during each session.

The Extension Agent served as the coordinator for the program. He/she determined the dates that the school would be held, determined where the school would be held, contacted local medical professionals and volunteers to assist with the program, publicized the program and the dates, conducted a registration, and made arrangements to receive all of the materials needed to conduct the cooking school.

The Dining with Diabetes program consisted of three two-hour sessions that were offered consecutively once a week over a three-week period and a 6-month follow-up session. The sessions were divided into desserts, main dishes, and side dishes. Each session began with a cooking demonstration provided by the Extension Agent followed 
by the nutrition education instruction provided by the RD, CDE, or RN. The taste testing was the final activity of each cooking school. The 6-month reunion consisted of a spring recipe theme.

\section{Session One: Desserts}

Participants registered during this session. Each participant received a numbered folder containing the Dessert Recipe packet that included the lesson and the recipes to be presented during the session. They also completed the numbered demographic form and pre-test. Following the cooking demonstration the nutrition education component of the program was presented. Several nutrition topics were taught during this session including the Diabetic Food Guide Pyramid, instructions on how to read a food label, and information concerning artificial sweeteners. Participants were encouraged to follow along in their packets during the cooking demonstration and the educational portion. Overhead transparencies were used in conjunction with the packet of information that the subject received for the nutrition education portion of the program. The participants then had the opportunity to taste the prepared recipes that consisted of carrot cake, apple-berry crisp, lemon cake, banana-pineapple delight and a double layer pumpkin pie.

\section{Session Two: Main Dishes}

Participants received the Main Dish Recipe packet prior to the beginning of the session. Session two focused on saturated fat and the negative impact it has on the body. Monounsaturated fats were discussed as healthier alternatives. Information on substituting herbs and spices in place of salt was also provided during the educational component of the program. Spicy grilled chicken, oven-poached fish, Italian beef stirfry, baked pork chops, and spinach lasagna were prepared and tasted during this session. 


\section{Session Three: Side Dishes}

Participants were provided with a Side Dish Recipe packet for this session.

Double corn bread, glazed carrots, spinach salad, cole slaw, and four-bean salad were prepared during the third session. The educational component of this session focused on low-fat dairy products, preparing fruits and vegetables, fiber in the diet, and the Plate Method in meal planning.

\section{The 6-month Reunion}

The reunion provided an opportunity for the participants to come together and share ideas and recipes. No formal educational component existed for this session, however a cooking demonstration was presented as well as a time for tasting the recipes. The participants completed the posttest during this session.

\section{Instruments}

The data collection instruments consisted of a demographic form and a pre/posttest form. The demographic form examined diabetes status, gender, age, ethnicity, general health, food shopping for the household, and preparation of food in the home (Appendix A). The pre/posttest consisted of 7 knowledge questions and 12 questions intended to measure behavior and associated diabetes related practices (Appendix B).

\section{Nutrition Knowledge Score Validation}

The nutrition knowledge assessment portion of the questionnaire was validated using the STATISTICA data analysis program version 5.5 (StatSoft, 1999). Pearson's correlation coefficient (r) was used to test for validity. These results are given in Table 1. Each nutrition knowledge question from the pretest was regressed to the total score for 
the pretest. All questions that were positively correlated $(\mathrm{p}<0.06)$ with the total pretest were accepted for evaluation. The sub-question "corn oil" which was part of question 5, "Check all of the following foods that are high in monounsaturated fat." was not significantly correlated $(\mathrm{p}>0.086)$ and was negative as well $(\mathrm{r}=-0.07)$. For this reason, this sub-question was deleted from the scoring system and the remaining thirty subquestions were accepted for analysis.

\section{Nutrition Knowledge Score}

Pretest and posttest nutrition knowledge scores were determined for each participant. This process was determined by a point system for each question. Each knowledge question was broken down into sections, for example question one was broken into ten sub-questions and was worth 10 points. A point was given if the subject indicated a correct answer. As an example in question 1, "Check each of the following foods that are rich sources of carbohydrate." If the food item was a rich source of carbohydrate and the subject marked that food item, a point was given and if the food source was not marked they received a zero. If the food item was not rich in carbohydrate and it was not marked a point was given, however if it was marked, the subject received a zero. Subjects who left an entire knowledge question blank received no points for that question. This system was used for each of the seven knowledge questions and a total pretest knowledge score and posttest knowledge score was determined by adding the total points. A total score of thirty points were possible. 


\section{Behavior Score}

The remainder of the pre/posttest questionnaire was analyzed using the scoring system located in Appendix C. This scoring system was completed for the pretest and posttest and was utilized for questions 8-19. 


\section{Chapter IV}

\section{Results}

Descriptive statistics provided the demographic characteristics of the study population. Although 591 subjects completed the pretest, only 208 subjects completed both the pretest and posttest. This indicates that $35 \%$ of subjects that completed a pretest also completed a posttest.

Table 2 shows the diabetic status of the study population. As indicated in the table, $54.7 \%$ of the subjects were diabetic, $39.6 \%$ were not diabetic, and $5.7 \%$ of the subjects belonged to the "other" group. The "other" group consisted of subjects who did not answer the question about diabetes status or indicated that they were not sure if they had diabetes or not.

Gender characteristics of the study population are given in Table 3 . The study population consisted of 512 females, $86.6 \%$ of the population, and there were 76 male subjects, $12.9 \%$. The remaining $0.5 \%$ of the subjects belonged to the "other" group, which means that some subjects did not indicate their gender.

The demographic data indicated that the majority of subjects were white/nonHispanic individuals. This information is given in Table 4. The white/non-Hispanic group accounted for $94.1 \%$ of the study population's ethnicity. The Native American/American Indian group comprised the next to highest percentage with 2.88\%.

Table 6 gives the age groups of the study population. The greatest number of subjects were between the ages of 51-80 years of age. These three age groups comprised $74.1 \%$ of study population. 


\section{Nutrition Knowledge}

Analysis of variance (ANOVA) was used to evaluate the mean differences between pre- and posttest nutrition knowledge scores of diabetic and non-diabetic subjects. The mean knowledge pretest scores (mean score \pm standard deviation) were $21.0 \pm 4.4$ for diabetic subjects $(\mathrm{N}=313)$ and $20.8 \pm 4.0$ for non-diabetic subjects $(\mathrm{N}=226)$. The mean knowledge posttest scores were $22.5 \pm 4.0(\mathrm{~N}=129)$ for diabetic subjects and $22.5 \pm 4.8(\mathrm{~N}=79)$ for non-diabetic subjects. No significant differences in total nutrition knowledge score were found between diabetic and non-diabetic subjects.

Each subject was placed into one of three groups based on their pretest nutrition knowledge score. The group number indicated the scholastic status of the subjects. Subjects who scored a total of 24 points or greater $(80 \%-100 \%)$ were assigned to Group 3. Group 2 consisted of subjects who scored greater than 15 points, but less than 24 points $(50-79 \%)$. Those subjects who scored less than $15(<50 \%)$ were assigned to Group 1.

Two-factor ANOVA was done to measure variance of the total pretest knowledge score (dependent variable) with diabetic status and scholastic status (independent variables). The results of this analysis are shown in table 6 . These results indicate that diabetes status was not significantly associated with nutrition knowledge score. As expected, scholastic status was significantly associated with nutrition knowledge score. This significance was present because similar scores were placed in the same group. For example, all subjects who scored $<15$ points on the pretest were placed in Group 1 . The results also showed interaction for nutrition knowledge score between student groups and diabetic status $(\mathrm{p}<0.07)$. 
Figure 1 provides a clearer picture of this interaction. The figure shows that diabetic subjects in Group 1 had lower mean knowledge scores than non-diabetic subjects. The figure shows that diabetic and non-diabetic subjects in Group 2 had similar knowledge scores and that diabetic subjects in Group 3 had higher mean scores than nondiabetic subjects in that group. Thus, independently the factors (diabetes status and scholastic status) had no significant effect on nutrition knowledge score, however significant interaction was indicated for these two factors.

A comparison of mean pretest knowledge scores between diabetic status and scholastic status is given in table 7. As described earlier, diabetic subjects in Group 1 had lower mean knowledge scores $(11.5 \pm 3.5)$ than non-diabetic subjects $(12.7 \pm 1.7)$. The scores for Group 2 were nearly the same for diabetic subjects $(19.9 \pm 2.3)$ and nondiabetic subjects $(20.0 \pm 2.2)$. Diabetic subjects in Group 3 had a higher mean knowledge score $(25.9 \pm 1.8)$ than non-diabetic subjects $(25.4 \pm 1.4)$.

Correlation analysis was done to measure the linear relationship between total pretest knowledge score and the change in score (posttest score - pretest score). Figure 2 shows that the relationship between the total pretest knowledge score and change in score was significant $(\mathrm{p}<0.00)$ and was negatively correlated (Pearson's correlation coefficient, $r=-0.75)$. Thus, subjects who scored low in the pretest had a greater positive change in score and subjects who received high pretest scores actually had less changes in score.

\section{Association of Nutrition Knowledge with Behavior and Diabetes Practices}

Pearson's correlation was conducted determine the association of nutrition knowledge with self-reported behavior and related diabetic practices. The total scores 
from the pre and post-tests were compared with questions measuring behaviors and practices (questions 8-19). These results are given in table 8. The results show a significant association of nutrition knowledge with several of the behaviors and practices.

Questions 9, 10, and 18 showed significant association with nutrition knowledge only for the pretest. Question 9, "Do you use olive or canola oil?" was significantly correlated with nutrition knowledge $(\mathrm{r}=0.164, \mathrm{p}<0.000)$. Significant association was also indicated for question 10, "Do you use artificial sweeteners in desserts?" $(\mathrm{r}=0.116, \mathrm{p}<0.008)$ and question 18 , "How hard or easy would it be for you to prepare healthy meals for someone with diabetes?" $(\mathrm{r}=0.086, \mathrm{p}<0.046)$.

Areas of significant association were indicated for several variables in the posttest that were not present in the pretest. Question 15, "Following a healthy meal plan helps to control diabetes," was significantly correlated with nutrition knowledge for the posttest $(\mathrm{r}=0.170, \mathrm{p}<0.014)$. Question 16, "Controlling my blood sugar is important to me," was also significantly correlated with nutrition knowledge for the posttest $(\mathrm{r}=0.151, \mathrm{p}<0.048)$.

Significant association was indicated in both the pretest and posttest scores for questions 8 and 14. Question 8, "Do you use herbs or spices in place of salt?" significantly associated with nutrition knowledge for the pretest and posttest $(\mathrm{r}=0.123$ for the pretest, $\mathrm{r}=0.168$ for the posttest). Question 14, "I know how to use Nutrition Facts labels found on packaged foods to prepare healthy meals," was also found to be significantly associated with nutrition knowledge ( $\mathrm{r}=0.117$ for the pretest, $\mathrm{r}=0.238$ for the posttest score). 


\section{Healthy Meal Plan}

The percentage of problems associated with following a healthy meal plan, from question 19, is given in tables 9 and 10. Table 9 gives the percentages of problems with following a diabetes meal plan for the pretest. They are given in order from the highest to lowest percentage. At the pretest, participants classified the three greatest problems with using a diabetes meal plan as: "too confusing" with $24.1 \%$, "not enough time" with $22.4 \%$, and "don't know how to get started" with $19.8 \%$.

Table 10 gives the percentage of problems associated with using a diabetes meal plan in the posttest. The three greatest problems associated with using a diabetes meal plan at the posttest were: "family won't eat it" with $23.9 \%$, "other" with $20.6 \%$, and "not enough time" with $19.7 \%$. Interestingly, the option indicated as the greatest problem in the pretest, "too confusing" decreased from $24.1 \%$ to $18.3 \%$ in the posttest. 
Table 1: Validation of Knowledge Questionnaire ( $N=577), p<0.06$

Variable r-value

Question 1

Hamburger patty $\quad 0.33$

Apple $\quad 0.40$

Cookie $\quad 0.44$

Bread $\quad 0.33$

Potato $\quad 0.35$

Milk $\quad 0.26$

Orange juice $\quad 0.41$

Sugar $\quad 0.38$

Olive oil $\quad 0.30$

Butter $\quad 0.30$

Sum of Question $1 \quad 0.71$

Question 2

Aspartame $\quad 0.43$

Saccharin $\quad 0.40$

Acesulfame Potassium $\quad 0.40$

Sucralose $\quad 0.43$

Sum of Question $2 \quad 0.53$

Question 3 0.26

Question 4

Butter 0.31

Olive oil $\quad 0.31$

Lard $\quad 0.34$

Corn oil $\quad 0.26$

Sum of Question $4 \quad 0.42$

Question 5

Butter

0.44

Olive oil

0.46

Lard

0.45

Corn oil

$-0.07$

Sum of Question $5 \quad 0.47$

Question 6

Provide roughage $\quad 0.27$

Quick source of energy $\quad 0.19$

Rid of cholesterol $\quad 0.33$

Slow absorption of glucose $\quad 0.30$

Sum of Question $6 \quad 0.48$

Question 7

Starch

0.36

Sugar

0.30

Total fat

0.34

Cholesterol

0.31

Sum of Question 7

0.42 
Table 2: Diabetic Status of the Participants

\begin{tabular}{|l|c|c|}
\hline Diabetic Status & Number of Population & Percentage of Population \\
\hline Diabetics & 323 & $\mathbf{5 4 . 7 \%}$ \\
\hline Non-Diabetics & 234 & $\mathbf{3 9 . 6 \%}$ \\
\hline Other & 34 & $\mathbf{5 . 7 \%}$ \\
\hline Total & 591 & $\mathbf{1 0 0 \%}$ \\
\hline
\end{tabular}


Table 3: Gender Characteristics of the Study Population

\begin{tabular}{|l|c|c|}
\hline \multicolumn{1}{|c|}{ Gender } & Number of Population & Percentage of Population \\
\hline Female & 512 & $\mathbf{8 6 . 6 \%}$ \\
\hline Male & 76 & $12.9 \%$ \\
\hline Other & 3 & $0.5 \%$ \\
\hline Total & 591 & $100 \%$ \\
\hline
\end{tabular}




\section{Table 4: Ethnic Groups Represented by the Study Population}

\begin{tabular}{|l|c|c|}
\hline \multicolumn{1}{|c|}{ Ethnic Group } & Number of Population & Percentage of Population \\
\hline White/Non-Hispanic & 556 & $\mathbf{9 4 . 1 \%}$ \\
\hline White/Hispanic & 4 & $\mathbf{0 . 6 8 \%}$ \\
\hline African-American & 3 & $\mathbf{0 . 5 1 \%}$ \\
\hline Asian-American & 2 & $\mathbf{0 . 3 4 \%}$ \\
\hline $\begin{array}{l}\text { Native American/ } \\
\text { American Indian }\end{array}$ & 17 & $\mathbf{2 . 8 8 \%}$ \\
\hline Other & 9 & $1.52 \%$ \\
\hline Total & 591 & $100 \%$ \\
\hline
\end{tabular}


Table 5: Age Groups Represented by the Study Population

\begin{tabular}{|l|c|c|}
\hline Age in Years & Number of Population & Percentage of Population \\
\hline $20-30$ & 15 & $2.5 \%$ \\
\hline $31-40$ & 25 & $4.2 \%$ \\
\hline $41-50$ & 92 & $15.6 \%$ \\
\hline $51-60$ & 166 & $28.1 \%$ \\
\hline $61-70$ & 156 & $26.4 \%$ \\
\hline $71-80$ & 116 & $19.6 \%$ \\
\hline $81-90$ & 12 & $2.0 \%$ \\
\hline Other & 9 & $1.5 \%$ \\
\hline Total & 591 & $100 \%$ \\
\hline
\end{tabular}


Table 6: Results of ANOVA, Nutrition Knowledge Score, with Diabetes Status and Scholastic Status Groups

\begin{tabular}{|l|l|l|l|l|l|}
\hline Effect & SS & $\begin{array}{l}\text { Degrees of } \\
\text { Freedom }\end{array}$ & MS & F & p \\
\hline $\begin{array}{l}\text { Diabetes } \\
\text { Status }\end{array}$ & 4.23 & 1 & 4.23 & 0.91 & 0.34 \\
\hline $\begin{array}{l}\text { Scholastic } \\
\text { Status }\end{array}$ & 6791.23 & 2 & 3395.62 & 728.99 & 0.00 \\
\hline $\begin{array}{l}\text { Diabetic x } \\
\text { Scholastic } \\
\text { Status }\end{array}$ & 26.24 & 2 & 13.12 & 2.82 & 0.06 \\
\hline Error & 2482.69 & 533 & 4.66 & & \\
\hline
\end{tabular}




\section{Figure 1: Nutrition Knowledge Score with Diabetic Status and Scholastic Status}

\section{$F(2,533)=2.82 ; p<0.06$}

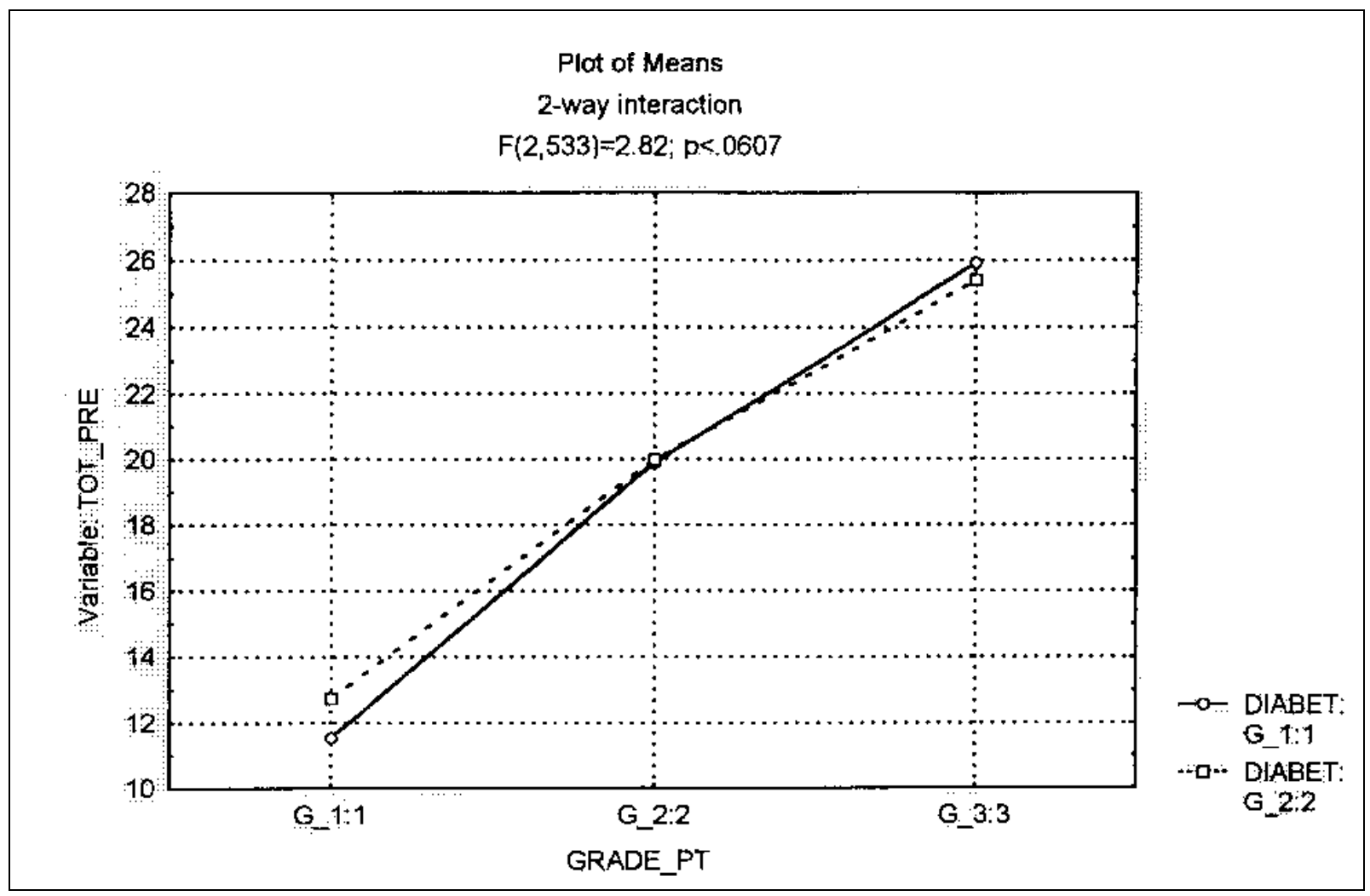

GRADE_PT $=$ the 3 scholastic groups

TOT_PRE $=$ the pretest score out of 30 maximum points 


\section{Table 7: Nutrition Knowledge Score of the Knowledge Questionnaire between Diabetic Status and Scholastic Status}

\begin{tabular}{|l|l|l|l|l|}
\hline Diabetic Status & $\begin{array}{c}\text { *Scholastic } \\
\text { Status }\end{array}$ & $\begin{array}{c}\text { Mean Nutrition } \\
\text { Knowledge Score } \\
\text { (Pre) }\end{array}$ & \multicolumn{1}{|c|}{$\begin{array}{c}\text { Standard } \\
\text { Deviation }\end{array}$} & N \\
\hline Diabetes & 1 & 11.5 & 3.5 & 22 \\
\hline Diabetes & 2 & 19.9 & 2.3 & 200 \\
\hline Diabetes & 3 & 25.9 & 1.8 & 91 \\
\hline & & & 20 \\
\hline No Diabetes & 1 & 12.7 & 1.7 & 147 \\
\hline No Diabetes & 2 & 20.0 & 2.2 & 59 \\
\hline No Diabetes & 3 & 25.4 & 1.4 & 539 \\
\hline All Groups & 20.9 & 4.2 & \multicolumn{2}{|l|}{} \\
\hline
\end{tabular}

\footnotetext{
*Scholastic Status: $1=$ subjects who scored $\leq 15$ points on pretest

$2=$ subjects who scored between 23-16 points

3 = subjects who scored $\geq 24$ points

$\mathrm{N}=$ number of subjects
} 
Figure 2: The Association Between Pretest Score and Change in Score Following the Posttest

Correlation: $r=-0.7530, p<0.00$

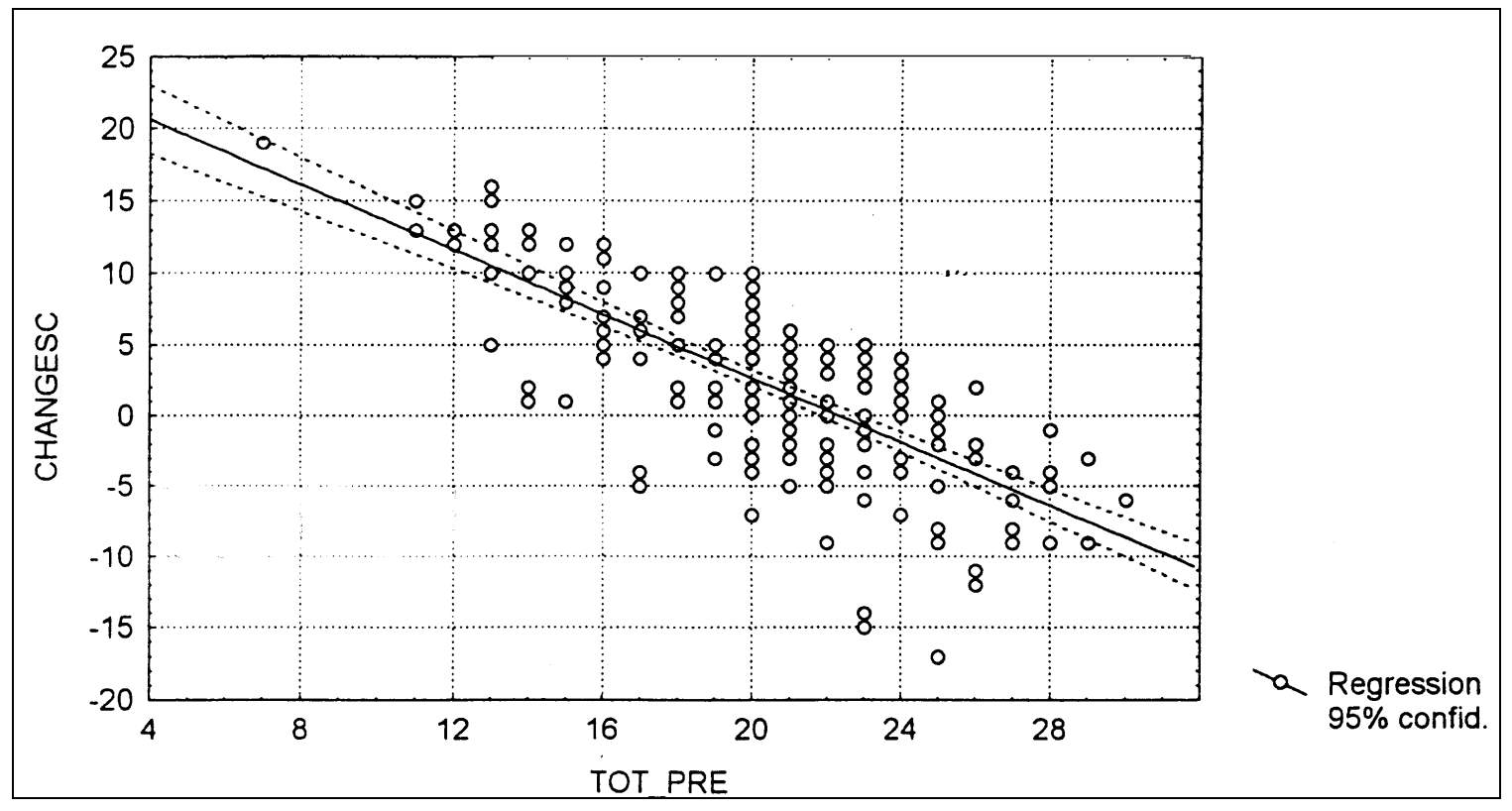

TOT_PRE $=$ the pretest score out of maximum 30 points

CHANGESC $=$ change in score, posttest score - pretest score 
Table 8: Association Between Nutrition Knowledge Score and Self-reported Behavior and Related Diabetes Practices

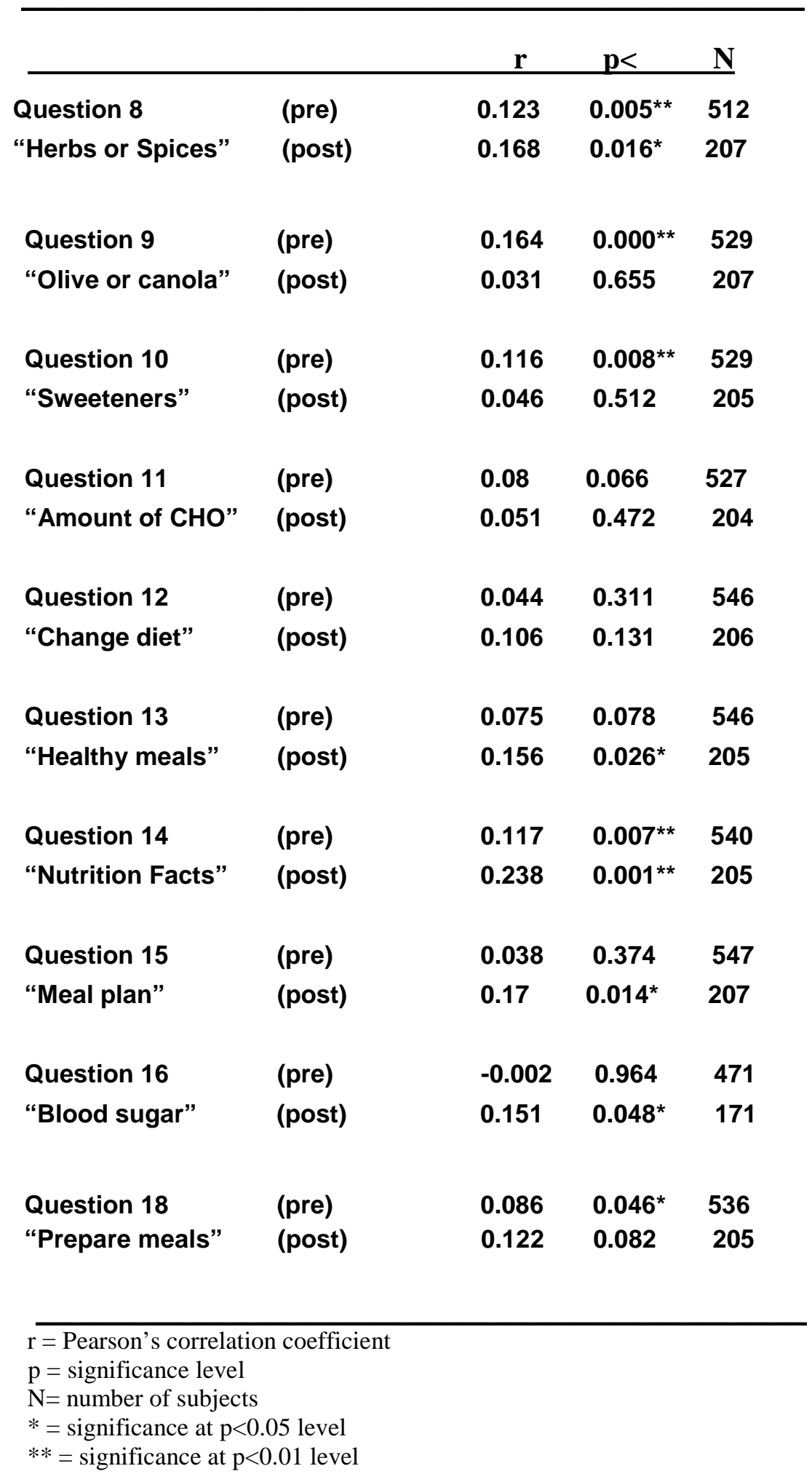


Table 9: Percent of Subjects in Each Problem Associated with Using a Diabetes Meal Plan (Pre-intervention)

\begin{tabular}{lr}
\hline \multicolumn{1}{c}{ Problem } & Percent \\
\hline Too confusing & 24.1 \\
Not enough time & 22.4 \\
Don't know how to get started & 19.8 \\
Family won't eat it & 17.5 \\
Too expensive & 17.2 \\
Other & 13.9 \\
Too hard to get started & 9.5 \\
Not motivated & 9.0 \\
Benefits not worth the effort & 6.9 \\
\hline Not real important to me & 6.9 \\
\hline N = 577 subjects & \\
\hline
\end{tabular}


Table 10: Percent of Subjects in each Problem Associated with Using a Diabetes Meal Plan (Post-intervention)

\begin{tabular}{lr}
\hline \multicolumn{1}{c}{ Problem } & Percent \\
\hline Family won't eat it & 23.9 \\
Other & 20.6 \\
Not enough time & 19.7 \\
Too confusing & 18.3 \\
Too expensive & 17.9 \\
Not motivated & 10.1 \\
Don't know how to get started & 5.0 \\
Too hard to get started & 5.0 \\
Not real important to me & 0.1 \\
Benefits not worth the effort & 0.0 \\
\hline $\mathrm{N}=218$ & \\
\hline
\end{tabular}




\section{Chapter V}

\section{Discussion}

\section{Nutrition Knowledge}

Following data analysis, no significant differences in nutrition knowledge were indicated for diabetic and non-diabetic subjects. A study by Bautista-Martinez et al. (1999), found that when measuring knowledge levels of Mexican individuals, patients with a greater number of clinical complications, especially Type 1 diabetics, had higher diabetes-related knowledge scores.

In the present study, diabetic subjects were not classified as Type 1 or Type 2; however, the majority of subjects are expected to be Type 2. This type of diabetes is the most prevalent form of diabetes. A greater risk for developing Type 2 diabetes occurs with increased age, weight, and sedentary lifestyle (American Diabetes Association, 1997). According to the results, $74.1 \%$ of the subjects were older individuals whose ages ranged from 51-80 years of age.

Although no weight measurements were examined in the present study, the percentage of overweight individuals in West Virginia is astonishing. According to Halperin et al. (1999) West Virginia is ranked fifth in the United States for obesity with $38.8 \%$ of the population falling into this category.

Often, because Type 2 diabetics are diagnosed with the disease later in life, they have fewer long-term complications compared to Type 1 diabetic subjects because of the severity of Type 1 diabetes. The above reasons may provide some explanation for the in significant findings in the knowledge scores of diabetic and non-diabetic subjects following the diabetes intervention program. 
Significant interaction for nutrition knowledge was indicated with diabetic status and scholastic status. Diabetic subjects in Groups 1 and 2 had lower mean pretest scores than non-diabetic subjects. However, this outcome was just the opposite for subjects in Group 3 in which diabetic subjects had higher mean knowledge pretest scores than nondiabetic subjects.

When mean pretest score was correlated with change in score, there was a trend for subjects with low pretest scores to have positive changes in score and subjects with high pretest scores to have negative changes in score. Subjects with lower initial scores had greater scores at the 6-month posttest, thus improving their scores. The subjects with higher pretest scores had lower scores on the posttest, thus their scores decreased from the pretest to the posttest. One outcome is discouraging given that subjects actually had lower nutrition knowledge scores following the diabetes intervention, but the other outcome is promising in that low-scoring subjects had improved nutrition knowledge scores following the intervention.

It is unclear as to why several of the subjects nutrition knowledge score was negatively correlated with change in score. One possible explanation is that those subjects with negative changes in score did not retain the information as readily as the subjects with positive changes in score. The older aged subjects may have had less memory, which negatively affected the posttest score.

This trend for negative change may have occurred because of subjects sharing answers. For example, subject A provided subject B with answers to some of the questions for the pretest. This may have caused subject B to score higher than he would have if he had completed the pretest based on his own knowledge. 
Another possible aspect may have been due to a lack of information and time during the nutrition education portion of each session. Approximately one hour was dedicated to nutrition education at each session. With such a limited teaching time it may have been difficult for the Registered Dietitian, Certified Diabetes Educator, or Registered Nurse to thoroughly cover the complex material.

\section{Behavior Change/Diabetes Practices}

It was found that nutrition knowledge was significantly correlated with several self-reported behaviors. Using herbs or spices in place of salt was associated with nutrition knowledge for the pretest and the posttest. So, it seems that subjects with higher nutrition knowledge scores were more likely to make this substitution. This association was also significant with using olive and canola oil and preparing desserts with artificial sweeteners, however only for the pretest score.

Several diabetic practices were also significantly associated with nutrition knowledge. The use of nutrition facts labels in preparing healthy meals was significantly associated with knowledge for both the pre and posttest. Difficulty in preparation of healthy meals for someone with diabetes was associated with knowledge for the pretest only. Most importantly, a significant association was found for several diabetes practices and nutrition knowledge at the posttest that was not significantly associated at the pretest. These practices were: "How sure are you that you can prepare healthy meals for someone with diabetes?" "Following a healthy meal plan helps to control diabetes." and "Controlling my blood sugar in important to me." Thus, as nutrition knowledge scores increased in the posttest, so did the incidence of these diabetic practices. 


\section{Meal Plan}

As indicated previously, subjects felt that following a healthy meal plan would help control diabetes. Following a healthy meal plan is very important for controlling diabetes. By controlling the amount of specific foods in the diet, especially carbohydrate foods, it may be possible for Type 2 diabetics to avoid insulin injections. Long-term complications such as retinal damage and lower limb amputations may also be avoided by following a healthy meal plan.

Results indicated that the greatest problem associated with using a diabetes meal plan in the pretest was that the information was too confusing. Following the diabetes intervention program, participants did not indicate that this was the greatest problem any longer. Thus, the diabetes intervention may have helped the subjects better understand the information so that it was not as confusing as it had originally been, however it was still rated as a major barrier to using a meal plan in the posttest. Subjects indicated that the greatest reason for not following a diabetes meal plan was that their families would not eat it. This may indicate that the participants prepared foods from a diabetic meal plan, or tried recipes they received as part of the "Dining with Diabetes" program and their families did not care for the foods, which may negatively impact the use of a diabetic meal plan.

\section{Limitations and Recommendations for Future Research}

The results indicate that there were several limitations of this study: a decreased number of participants returning for the 6-month posttest, the lack of sufficient male subjects, the small number of individuals form younger age groups, and the ethnic 
background of the subjects consisting of mainly white/non-Hispanic subjects. These factors may have negatively impacted the results of the present study.

The first limitation of the study was that only $35 \%$ of those subjects who completed the pretest also completed the posttest. This factor may have affected significance of the behaviors/practices, especially those behaviors that were significantly associated with nutrition knowledge in the pretest that were not significantly associated in the posttest. Graziani et al. (1999) found that individuals who did not attend diabetes education programs rated barriers to attendance as follows: lack of time 50\%, lack of transportation $38 \%$, trouble reading $25 \%$, poor vision $20 \%$, and trouble hearing $13 \%$. These factors may help indicate why the attendance at the 6-month reunion was decreased. Due to the amount of elderly subjects involved in this study, illiteracy, vision and hearing problems may have negatively affected attendance and thus the number of completed posttests.

Attendance may have also been affected due to poor weather conditions. The cooking schools were held between the months of September and November 1999 and the reunions were held between March and April 2000. Attendance at the cooking school sessions may have been negatively affected by inclement weather during these months.

In order to increase the participation of subjects in the 6-month reunion it may be important to send written letters to the participants or call them at home to remind them of the upcoming reunion. Using the newspaper as a resource may also be beneficial for announcing the upcoming reunion.

The second limitation identified by the results was that $86.6 \%$ of the subjects were females. This indicates that the male population needs to be targeted. The large 
percentage of female subjects who attended the intervention program may have attended in an effort to support their male spouses or family members or because they are the ones who prepare the food for diabetics. It is difficult to know the exact reason for this disproportionate attendance is caused by, however, it is pertinent that more male subjects attend the program for future research.

It is also important to target younger age groups of individuals. The majority of subjects in the present study were elderly. It is important that we reach these individuals, however it is also important to reach individuals who are younger. Involving younger aged people may help them prevent developing diabetes later in life. Possibly going out into the community and making younger age groups aware of the importance of diabetes education will attract them to the program.

Though most of the individuals in West Virginia are of white/non-Hispanic ethnicity, there are other ethnic groups in the state that could benefit from diabetes education. For example, African American individuals who have an increased risk for developing diabetes need to be involved. Offering programs in communities where major ethnic groups are not of the white/non-Hispanic background may easily solve this limitation.

These recommendations may allow improvements for further revisions of the Dining with Diabetes program. For further research, it would be very beneficial to involve more male subjects, a more diverse ethnic population and younger individuals. 


\section{Chapter VI}

\section{Conclusion}

The results showed that diabetes behaviors and practices were associated with

nutrition knowledge. Therefore, the Dining with Diabetes program has a positive effect on self-reported behaviors and diabetes related practices. 


\section{References}

Allwinkle, J. (1998). Role of education in the management of diabetes. Community Nurse, 4, 23-24.

American Diabetes Association. (1997). Report of the expert committee on the diagnosis and classification of Diabetes Mellitus. Diabetes Care, 20, 1183-1197.

Bautista-Martinez, S., Alberto, C., Aguilar-Salinas, Lerman, I., Velasco, L., Castellanos, R., Zenteno, E., Guillen, L., Murcio, R., Wong, B., Pe`rez, F., Rull-Rodrigo, J. (1999). Diabetes knowledge and its determinants in a Mexican population. The Diabetes Educator, 25, 347-381.

Block, G., Mandel, S., Miller, M., Harnak, L., Kayman, S., Cristofar, S. (2000). An interactive CD-ROM for nutrition screening and counseling. American Journal of Public Health, 90, 781-785.

Campbell, D., Stanley, J. (1963). Experimental and quasi-experimental designs for research. Chicago, IL: Rand McNally College Publishing Company.

Cardinal, B. J. (1995). Behavioral and biometric comparisons of the preparation, action, and maintenance stage of exercise. Wellness Perspectives, 11, 36-43.

Clark, N. M., Dodge, J. A. (1999). Exploring self-efficacy as a predictor of disease management. Health Education and Behavior, 26, 72-90.

Elder, J. P. \& Candelaria, J. L. (2000). Results of Language for Health: Cardiovascular disease nutrition education for Latino English-as-a second-language students. Health Education and Behavior, 27, 50-63.

Florence, J. A., \& Yeager, B. F. (1999). Treatment of Type 2 Diabetes Mellitus. American Family Physician, 59, 2835-2844. 
Graziani, C., Rosenthal, M. P., Diamond, J. J. (1999). Diabetes education program use and patient-perceived barriers to attendance. Family Medicine, 31, 358-363.

Hahn, J. M., \& Gordon, D. H. (1998). "Learn, Taste, and Share": A diabetes nutrition education program developed, marketed, and presented by the community. The Diabetes Educator, 24, 153-157.

Halperin, A. K., Elnicki, D. M., Palmer, H. C., See, C. J., Nuss, S., Kolar, M. M., Bell, D. (1999). Appalachian perspective on modifiable risk factors on coronary artery disease: How well are we doing? Southern Medical Journal, 92, 174-189.

Harvard Heart Letter (2000). Stages of Change: Getting to where you want to be. Harvard Heart Letter, 10, p. 4-6.

Herreria, J. (1999). "Control Your Diabetes" campaign encourages a healthy lifestyle. Profiles/Jan.-Feb. issue, 23-26.

Olson, C. (1999). "Dining with Diabetes": A cooking school program for people with diabetes and their families. Dining with Diabetes. Morgantown, WV.

Peyrot, M. (1999). Behavior change in diabetes education. The Diabetes Educator, 25, $62-73$.

Ridgeway, N. A., Harvill, D. R., Harvill, L. M., Falin, T. M., Forester, G. M., Gose, O. (1999). Improved control of Type 2 Diabetes Mellitus: A practical education/behavior modification program in a primary care clinic. Southern Medical Journal, 92, 667-672. 
Schoenberg, N. E., Amey, C. H., Coward, R. T. (1998). Diabetes knowledge and sources of information among African American and White older women. The Diabetes Educator, 24, 319-324.

Sorenson, G., Stoddard, A. (1998). The effects of a health promotion-health protection intervention on behavior change: The Wellworks Study. American Journal of Public Health, 88, 1685-1690.

StatSoft 5.5. (1999). Tulsa, OK: Statistica.

Taylor-Davis, S., Smiciklas-Wright, H., Warland, R., Achterberg, C., Jensen, G., Sayer, A., Shannon, B. (2000). Responses of older adults to theory-based nutrition newsletters. Journal of the American Dietetic Association, 100, 656-664.

USDHHS and the Centers for Disease Control and Prevention. (1999). Chronic diseases and their risk factors: The nation's leading causing of deaths. Atlanta, GA, 176.

West Virginia Bureau for Public Health. (1999). 1997 United States resident deathsLeading causes of death. Health Statistics Center, 70-71.

Zimmerman, G. L., Olsen, C. G., Bosworth, M. F. (2000). A 'Stages of Change' approach to helping patients change behavior. American Family Physician, 61, 1409-1417. 


\section{Appendices}


Appendix A 


\section{Dining with Diabetes - Demographics}

To help us learn more about you, please check the one best response to each of the following questions:

1. Do you have diabetes?

\begin{tabular}{l} 
Yes \\
\hline No \\
\hline
\end{tabular}

2. Do you choose most of the food used in your home?

Yes

No

3. Do you prepare most of the food eaten in your home?

Yes

No

4. What is your age?

5. Are you:

White/non-Hispanic;

White/Hispanic heritage

African-American/Black

Asian-American

Native American/American Indian

Other

6. Are you:

Female

Male

7. How would you describe your general health?

Excellent

Good

Fair

Poor 
Appendix B 


\section{Dining with Diabetes - Pretest/Posttest}

The following questions ask what you know about certain foods.

1. Check each of the foods that are rich sources of carbohydrate:

\begin{tabular}{l} 
Hamburger patty \\
\hline Apple \\
\hline Cookie \\
\hline Bread \\
\hline Potato
\end{tabular}

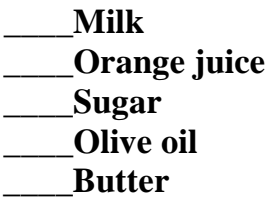

2. Check the sweetener that loses its sweet taste in baking.

Aspartame (Nutrasweet ${ }^{\mathrm{TM}}$ )

Saccharin (Sweet 'n Low ${ }^{\mathrm{TM}}$ )

Acesulfame Potassium (Sweet One ${ }^{\mathrm{TM}}$ )

Sucralose (Splenda ${ }^{\mathrm{TM}}$ )

3. When two kinds of artificial sweeteners are used together they are much sweeter than when either are used alone.

True

False

4. Check all of the following foods that are high in saturated fat.

Butter
Olive oil
Lard
Corn oil

5. Check all of the following foods that are high in monounsaturated fat.

Butter
Olive oil
Lard
Corn oil

6. Check all of the following reasons that fiber is important in the diet.

To provide roughage

To provide a quick source of energy

To help the body get rid of some of the cholesterol we eat

To help slow down absorption of glucose

7. Which one of the following is NOT usually printed on the Nutrition Facts Label on packaged foods?

Starch

Sugar

Total fat

Cholesterol 


\section{Dining with Diabetes - Pretest/Posttest}

(continued)

The following questions ask what you do about eating and preparing or following a diabetes meal plan.

8. Do you use herbs or spices in place of salt?

YES

If yes, how long have you been using herbs or spices in place of salt?

Less than six months

Six months or more

NO

If no, which one sentence best describes you:

I am not thinking of using herbs and spices in place of salt.

I am thinking about starting to use herbs and spices in place of salt.

I am definitely planning to use herbs and spices in place of salt in the next month.

9. Do you use olive oil or canola oil?

YES

If yes, how long have you been using olive oil or canola oil?

Less than six months

Six months or more

NO

If no, which one sentence best describes you:

I am not thinking of using olive oil or canola oil.

I am thinking about starting to use olive oil or canola oil.

I am definitely planning to use olive oil or canola oil in the next month.

10. Do you use artificial sweeteners in desserts?

YES

If yes, how long have you been using artificial sweeteners in desserts?

Less than six months

Six months or more

NO

If no, which one sentence best describes you:

I am not thinking of using artificial sweeteners in desserts.

I am thinking about starting to use artificial sweeteners in desserts.

I am definitely planning to use artificial sweeteners in desserts in the next month. 


\section{Dining with Diabetes - Pretest/Posttest (continued)}

11. Do you try to control the amount of carbohydrate you eat?

YES

If yes, how long have you been trying to control the amount of carbohydrate you eat?

Less than six months

Six months or more

NO

If no, which one sentence best describes you:

I am not thinking of trying to control the amount of carbohydrate I eat.

I am thinking about trying to control the amount of carbohydrate I eat.

I am definitely thinking about trying to control the amount of carbohydrate I eat.

12. How sure are you that you can change your diet to control the amount of carbohydrate you eat?
Very sure
Kind of sure
Kind of unsure
Very unsure

13. How sure are you that you can prepare healthy meals for someone with diabetes?
Very sure
Kind of sure
Kind of unsure
Very unsure

14. I know how to use Nutrition Facts labels found on packaged foods to prepare healthy meals.

Agree
Somewhat agree
Somewhat disagree
Disagree

15. Following a healthy meal plan helps to control diabetes.

Agree

Somewhat agree

Somewhat disagree

Disagree 


\section{Dining with Diabetes - Pretest/Posttest (continued)}

16. Controlling my blood sugar is important to me.

Agree
Somewhat agree
Somewhat disagree
Disagree
I don't have diabetes

17. How often do you test your blood sugar?

Once a day
Twice a day
Before every meal
Other
I don't test my blood sugar
I don't have diabetes

18. How hard or easy would it be for you to prepare healthy meals for someone with diabetes?

Very hard

Somewhat hard

Somewhat easy

Very easy

19. What problems do you have with using a diabetes meal plan?

Please check all that apply to you.

Not enough time

Too expensive

Too confusing

Family won't eat it

Don't know how to get started

Benefits now worth the effort

Not real important to me

Not motivated

Too hard to get started

Other 
Appendix C 


\section{Scoring System for Behavior Questions}

I. Question 8 "Do you use herbs or spices in place of salt?"

Question 9 "Do you use olive or canola oil?"

Question 10 "Do you use artificial sweeteners in desserts?"

Question 11 "Do you try to control the amount of carbohydrate you eat?"

$$
1=\text { yes, } 2 \text { = no }
$$

II. Question 12 "How sure are you that you can control the amount of carbohydrate you eat?"

Question 13 "How sure are you that you can prepare healthy meals for someone with diabetes?"

$$
3=\text { very sure, } 2=\text { kind of sure, } 1=\text { kind of unsure, } 0=\text { very unsure }
$$

III. Question 14 "I know how to use Nutrition Facts labels found on packaged foods to prepare healthy meals."

Question 15 "Following a healthy meal plan helps to control diabetes."

Question 16 "Controlling my blood sugar is important to me."

$$
3=\text { agree, } 2 \text { = somewhat agree, } 1=\text { somewhat disagree, } 0=\text { disagree }
$$

IV. Question 17, “How often do you test your blood sugar?”

This question was entered as the number of times per day that blood sugar was tested. If the value was less than once a day, the value was entered as a decimal value.

V. Question 18, "How hard or easy would it be for you to prepare healthy meals for someone with diabetes?"

$$
3=\text { very easy, } 2 \text { = somewhat easy, } 1=\text { somewhat hard, } 0=\text { very hard }
$$

VI. Question 19, “What problems do you have with using a diabetes meal plan?”

$$
1 \text { = indicated as a problem, } 2 \text { = not indicated as a problem }
$$




\section{Vita}

Name:

Parents:
Amy B. O'Dell

Arnold V. O'Dell

Ann P. O'Dell

\section{Education:}

West Virginia University, Morgantown, WV

Bachelor of Science in Family and Consumer Science, December 1998

West Virginia University, Morgantown, WV

Master of Science in Family and Consumer Science, December 2000

Professional Experience:

May 2000-December 2000

AP4 Dietetic Intern

West Virginia University, Morgantown, WV

Food Service Rotation completed through university facilities

Clinical Rotation completed at Monongalia General Hospital, Morgantown, WV

Community Rotation was completed at various sites throughout Monongalia County

January 1999-August 2000

Graduate Assistant

West Virginia University Extension Service, Morgantown, WV

"Dining with Diabetes" program 